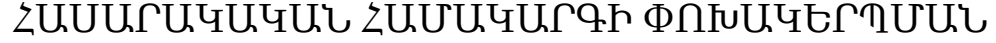

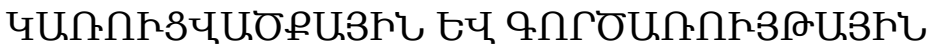

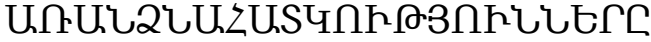

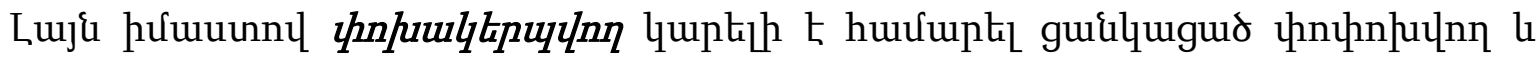

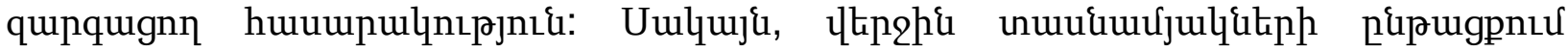

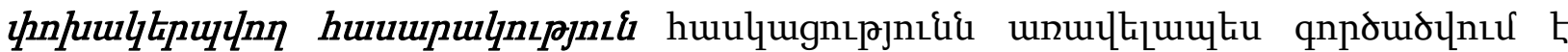

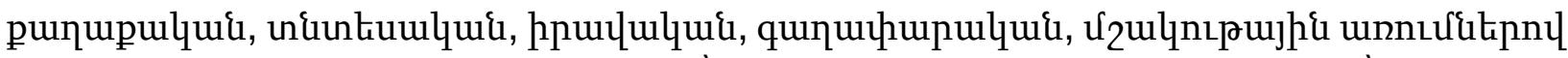

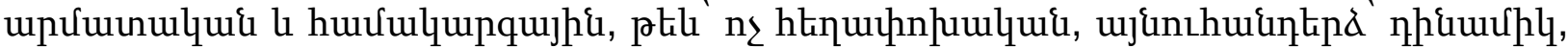

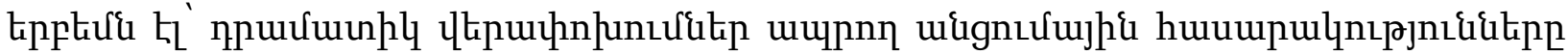
punıpuqptint hưưp:

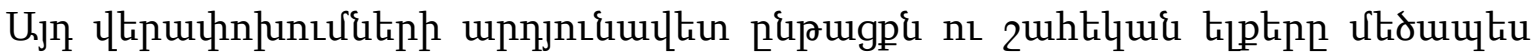

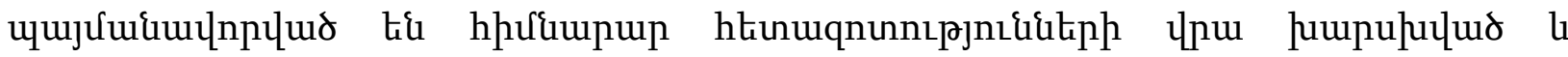

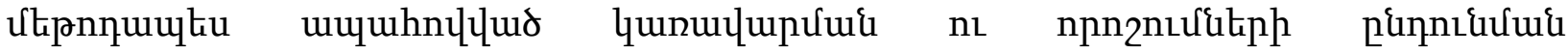
puqupulquintpjuúp:

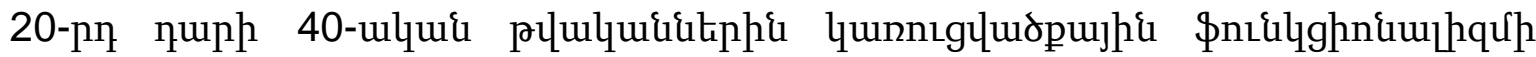

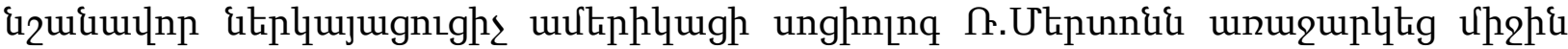

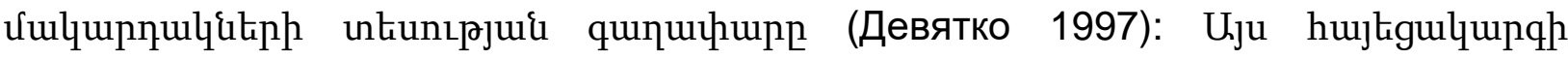

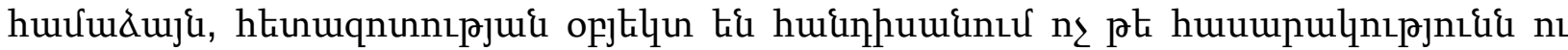

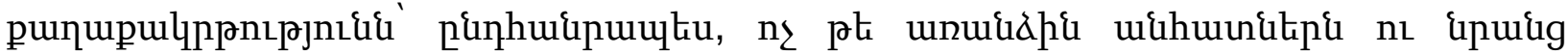

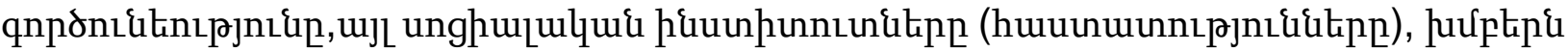
nı qnponipugitin:

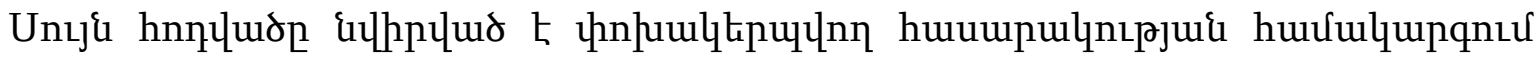

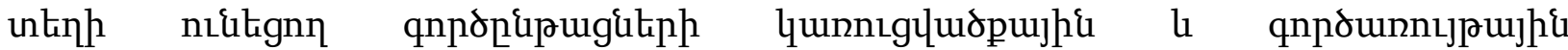

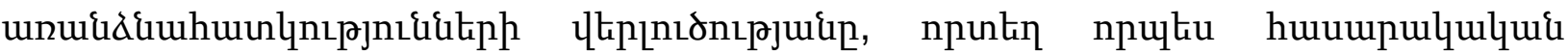

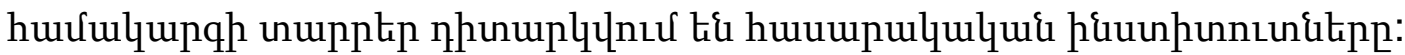

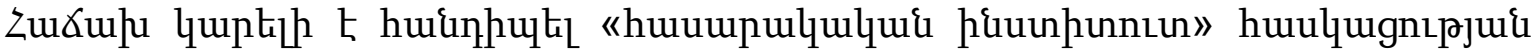

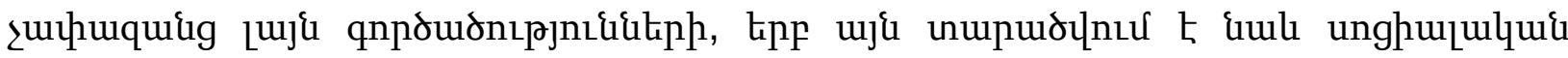

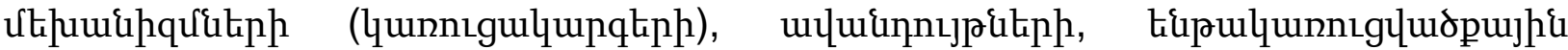

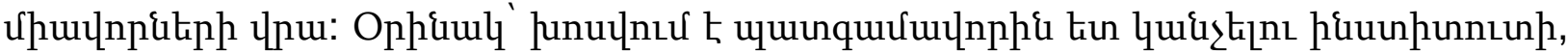

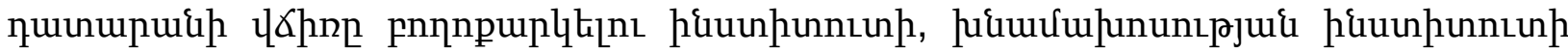

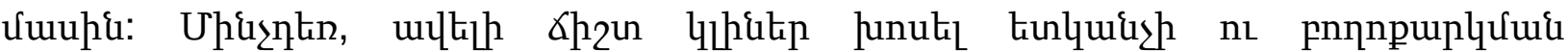

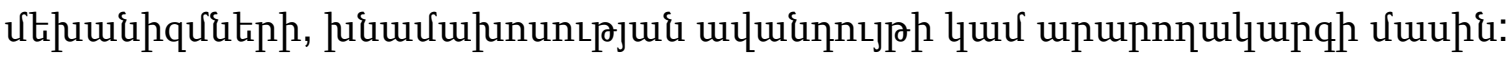

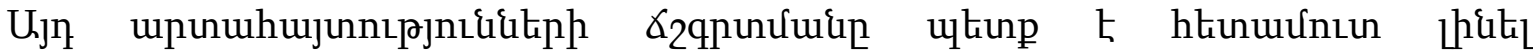

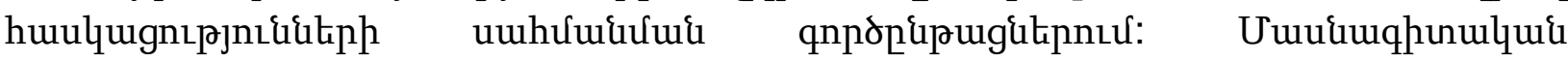

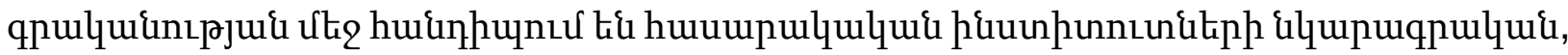

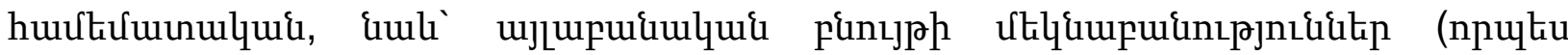

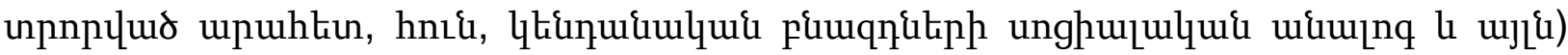
(Бергер 1996: 84-85, Кравченко 2001: 183-186):

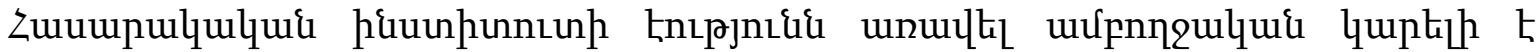

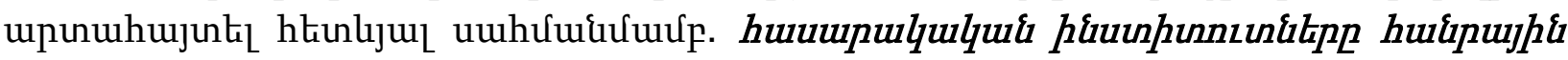

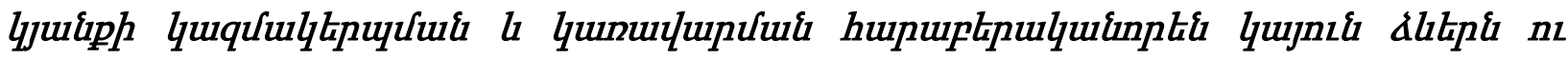

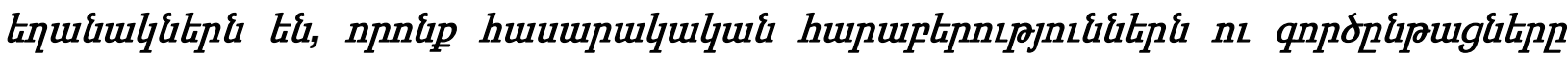

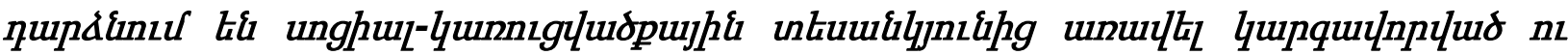

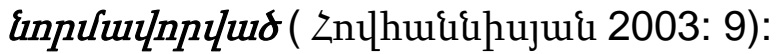




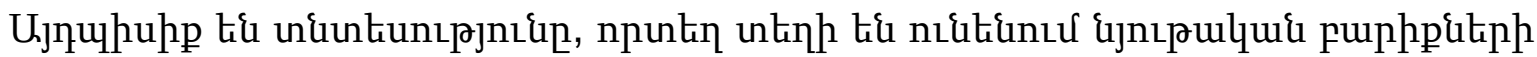

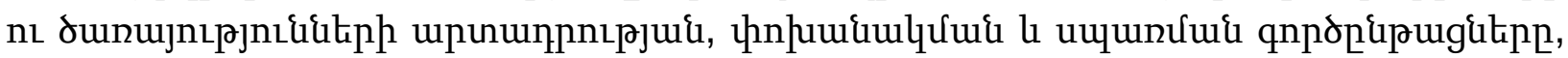

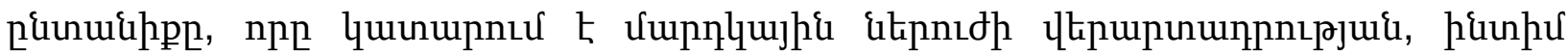

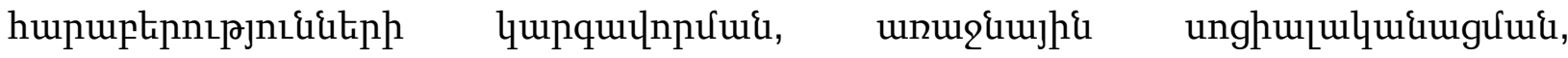

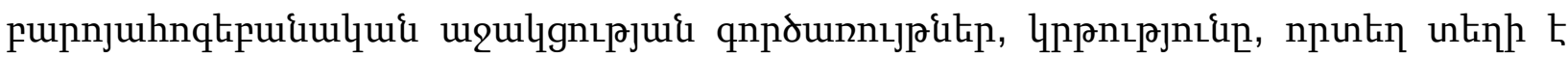

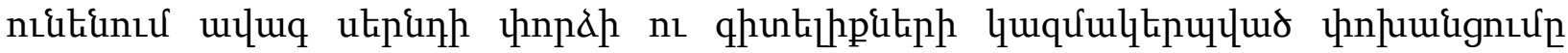

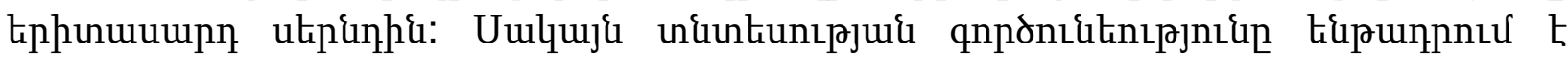

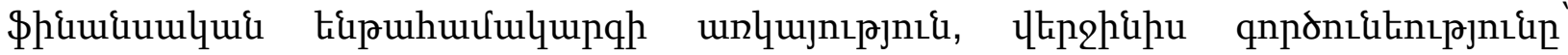

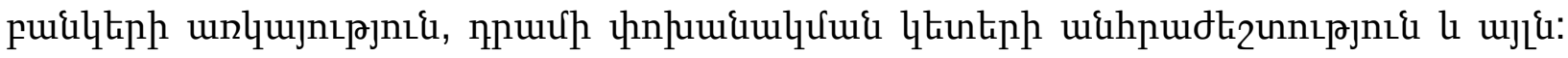

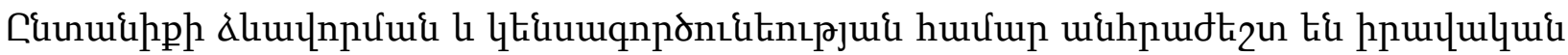

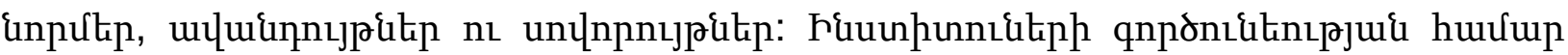

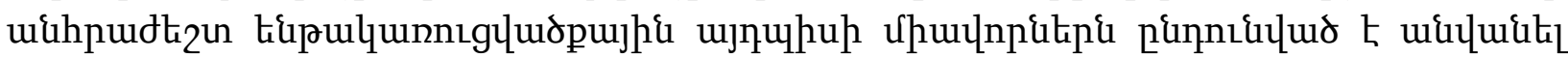

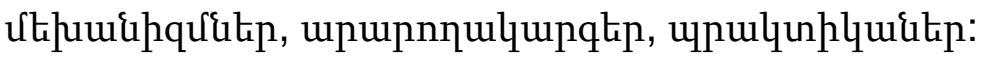

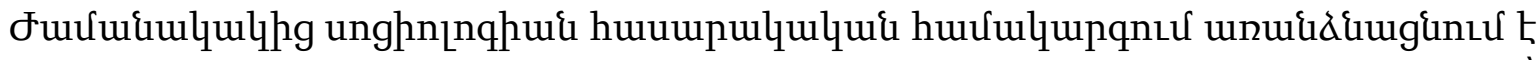

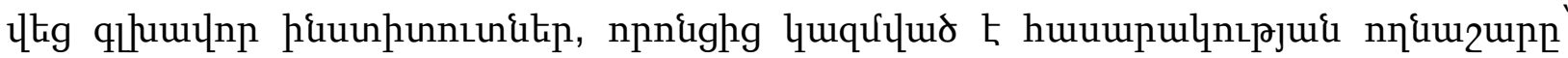

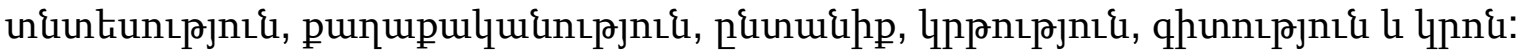

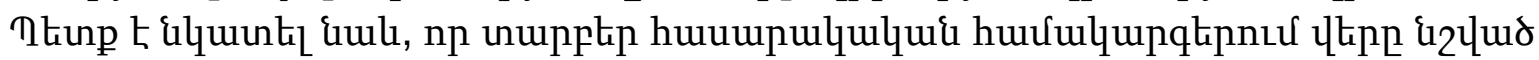

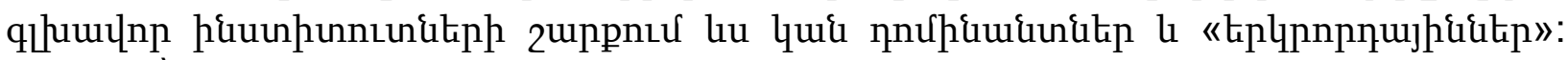

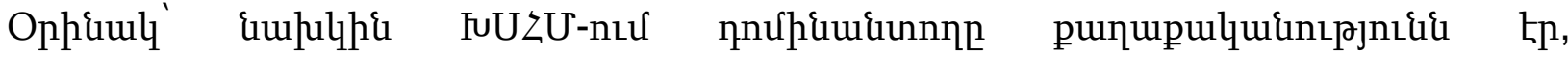

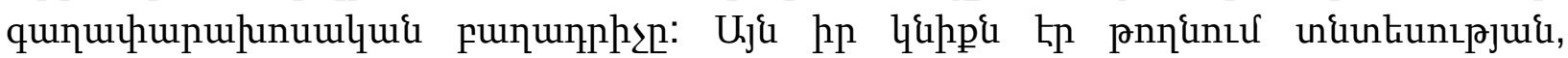

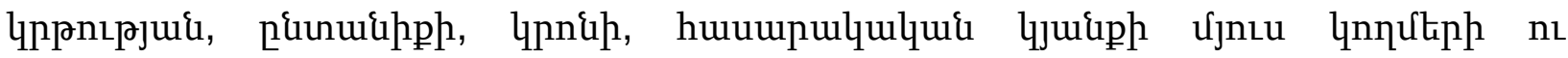

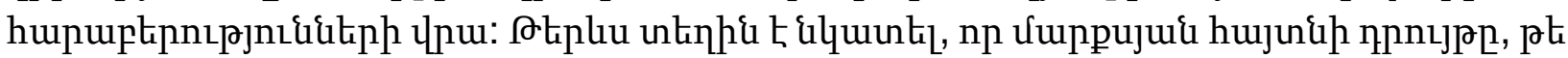

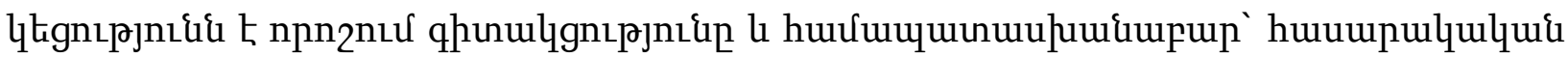

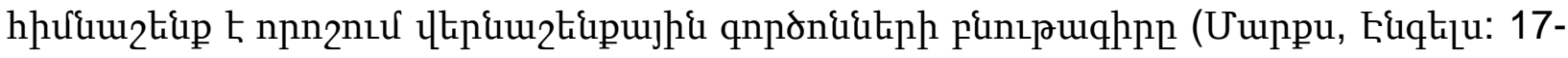

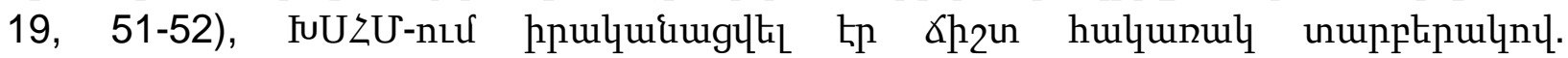

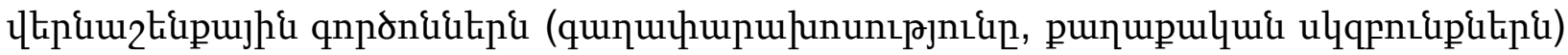

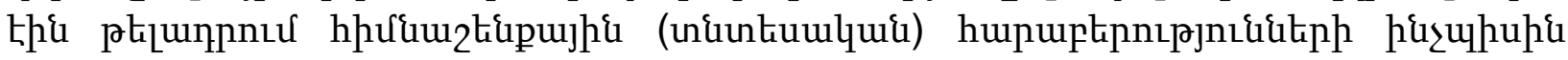
bitiln:

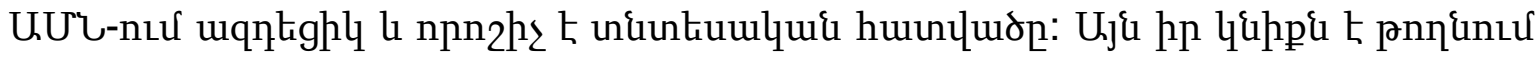

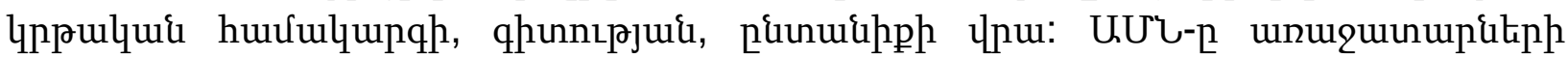

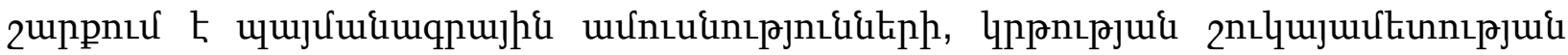

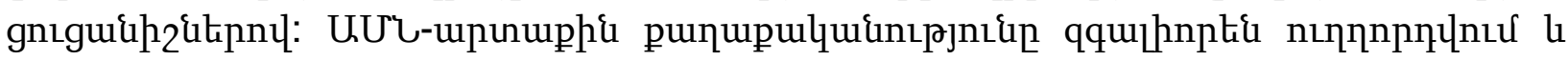

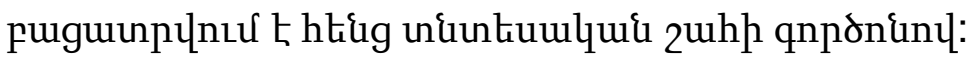

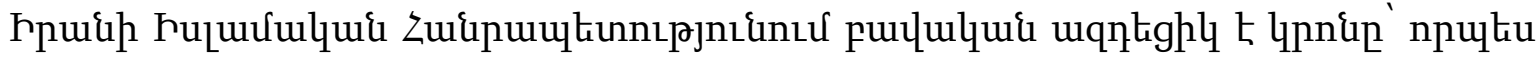

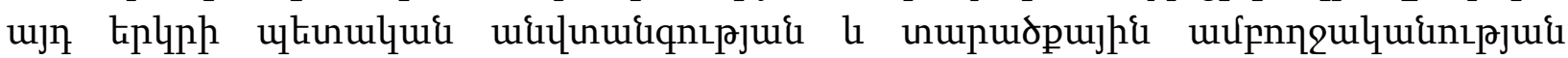

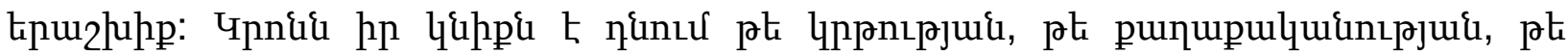

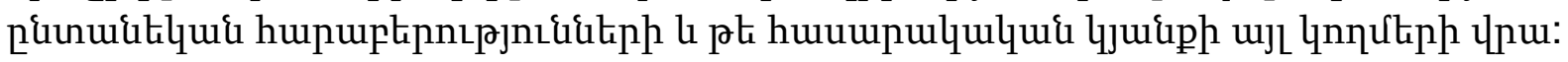

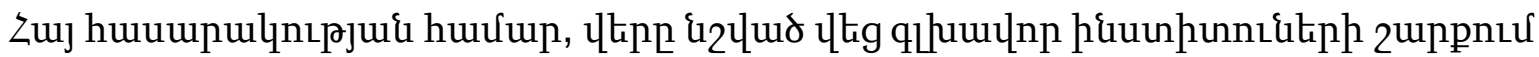

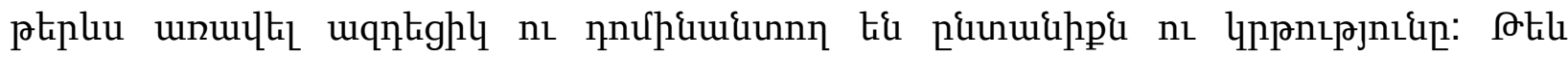

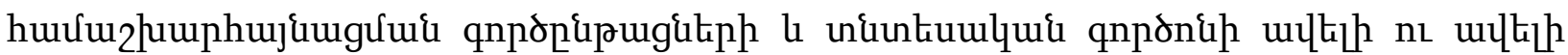

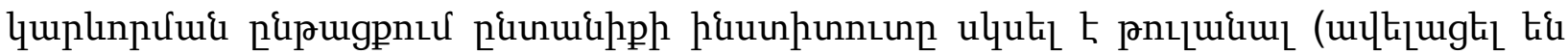

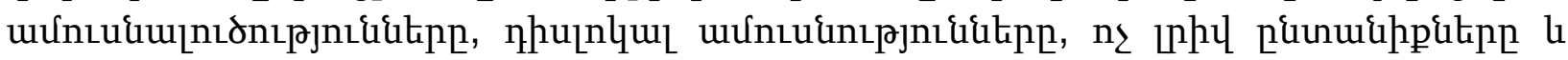

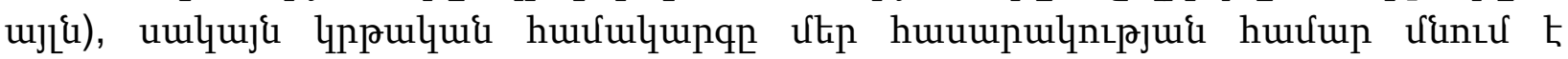

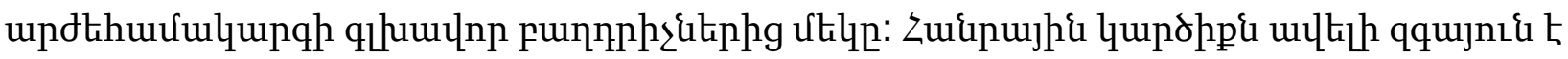

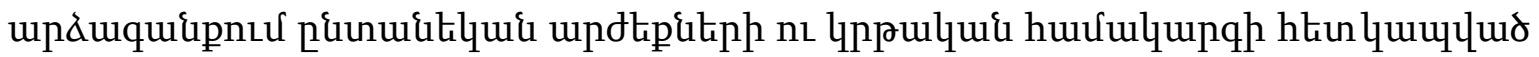


qnpopipugitiphi, puid uniuntuulquid

u2huuphnıu luuunuplnn

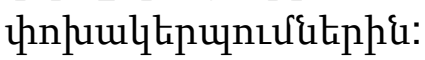

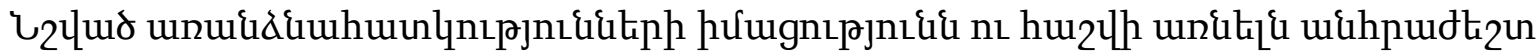

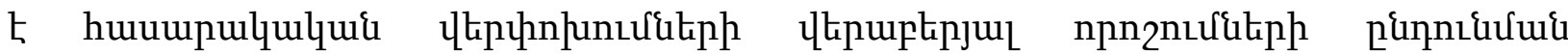

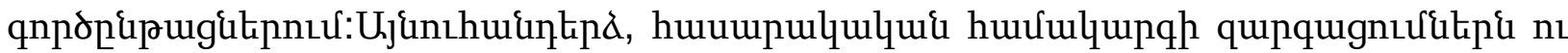

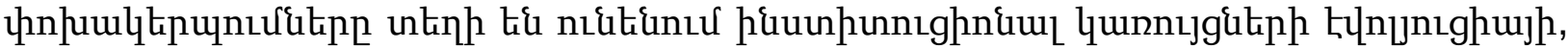

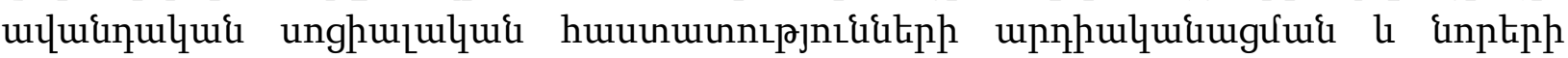

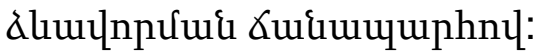

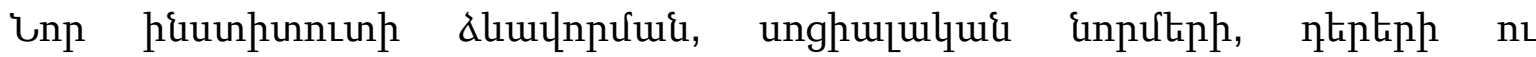

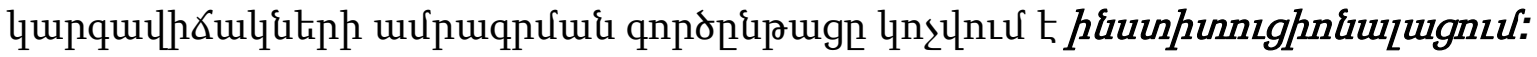

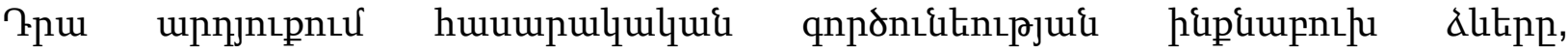

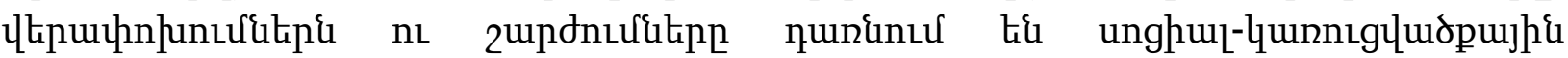

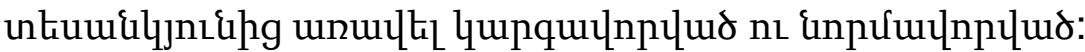

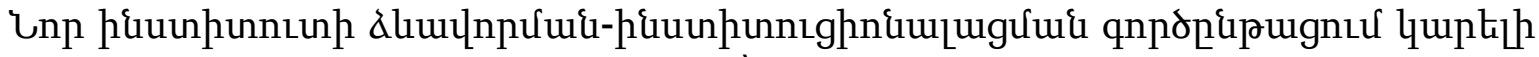

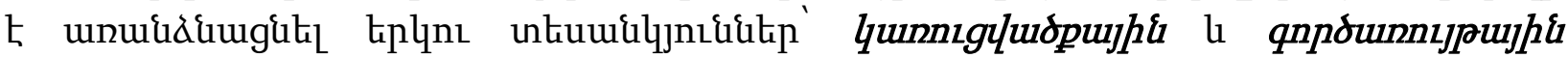
punumphriknp:

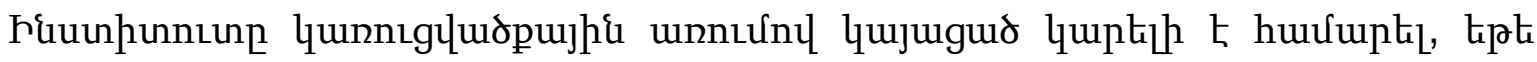

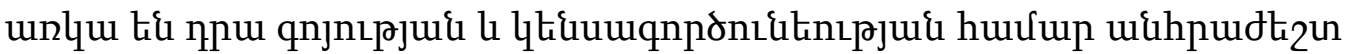

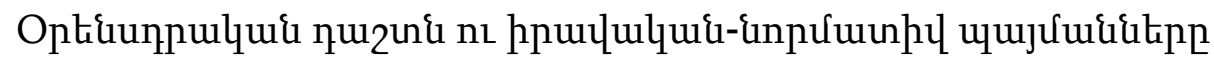

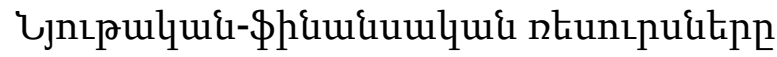

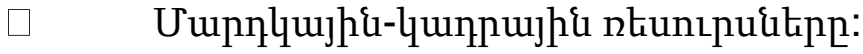

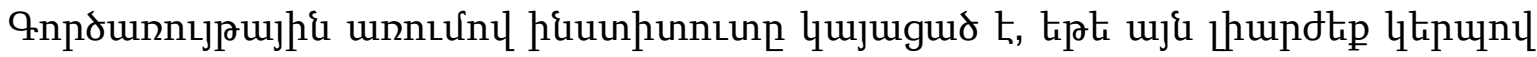
quunupnıর

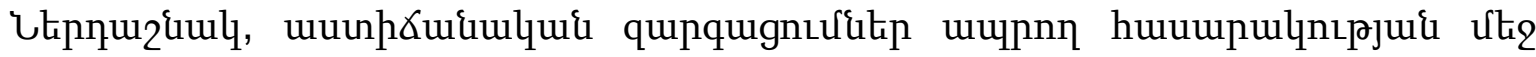

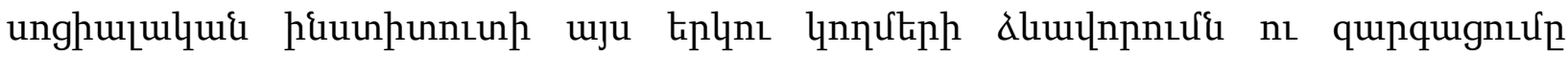

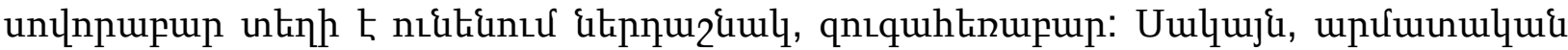

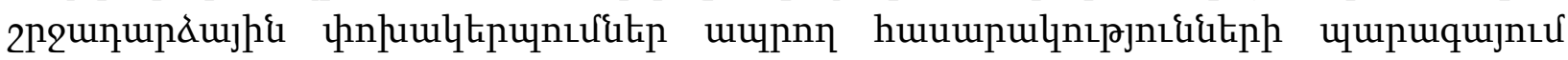

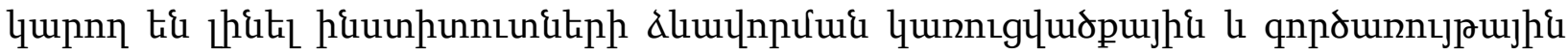

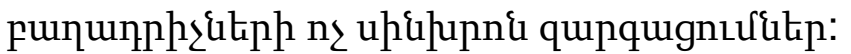

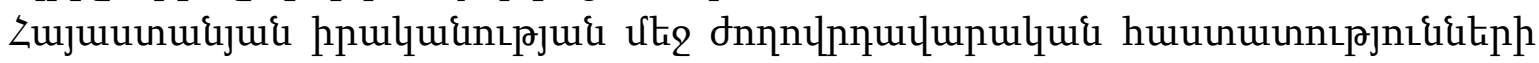

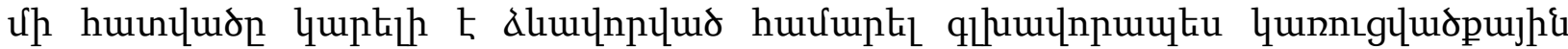

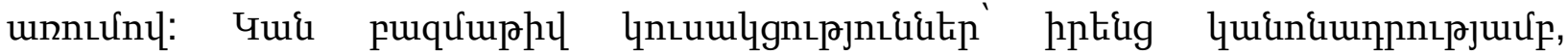

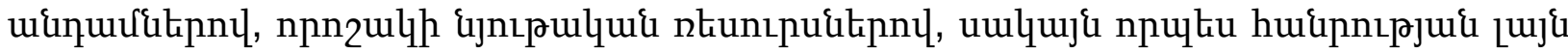

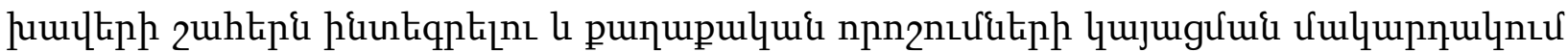

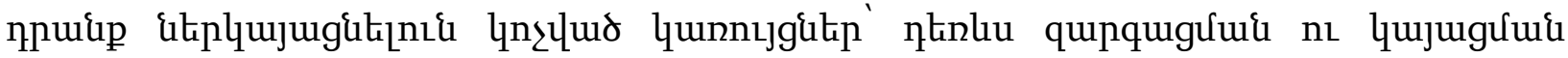

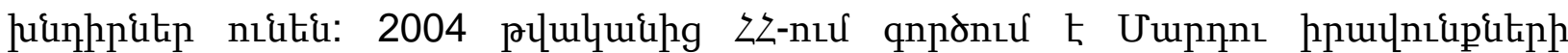

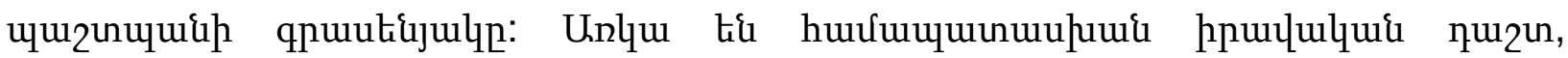

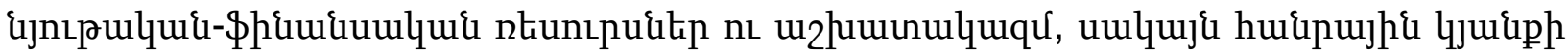

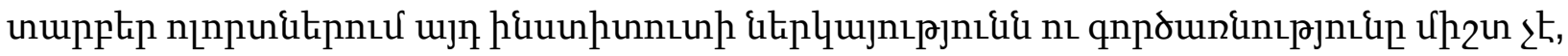

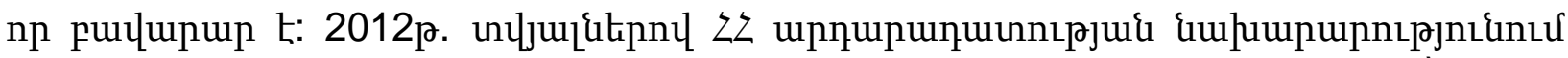

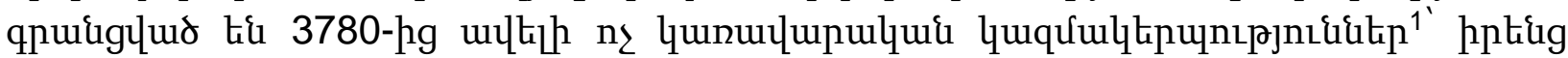

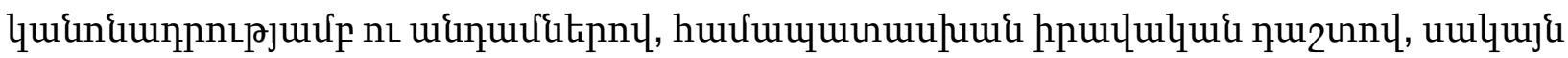

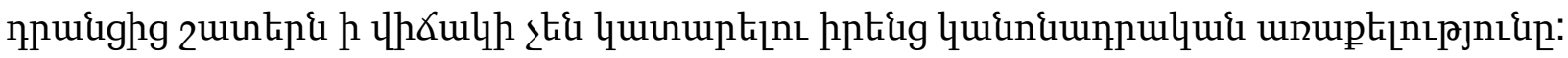




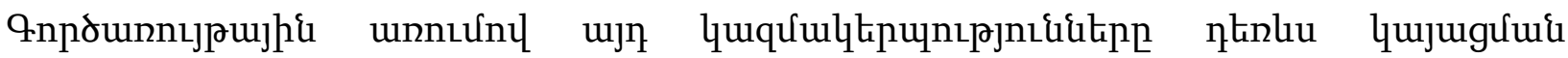

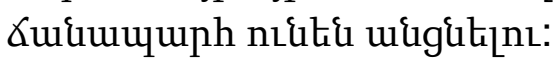

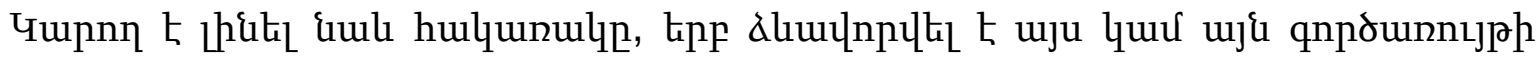

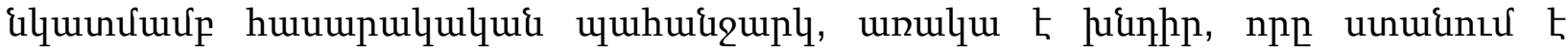

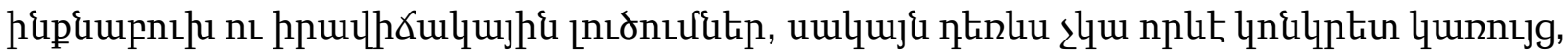

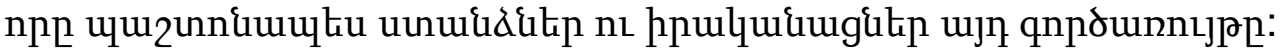

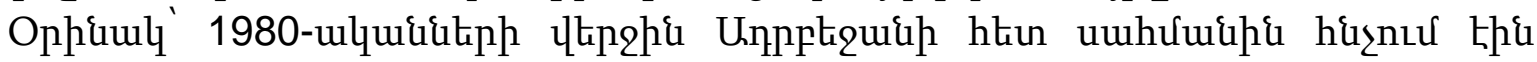

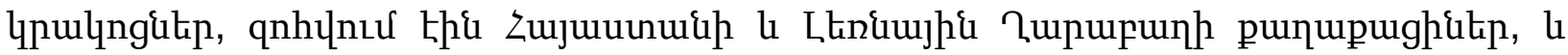

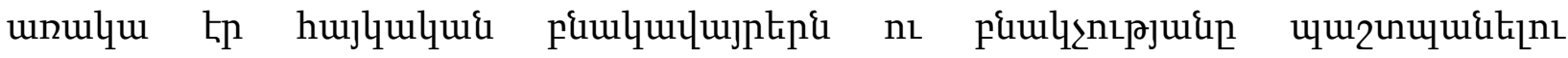

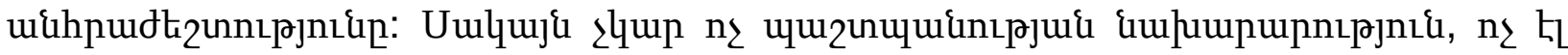

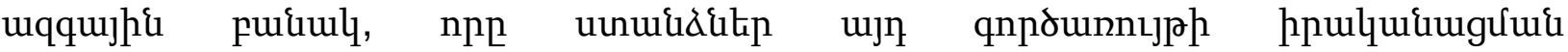

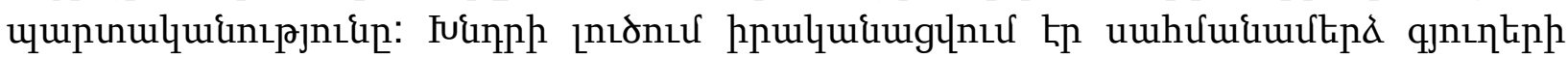

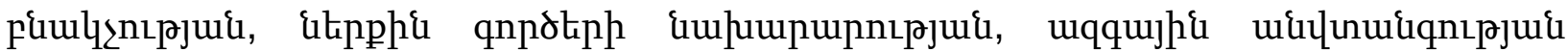

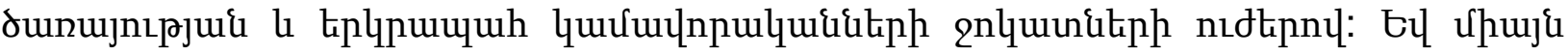

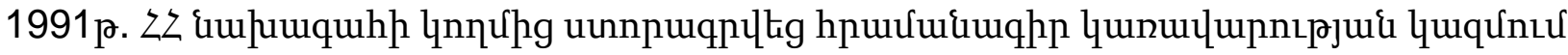

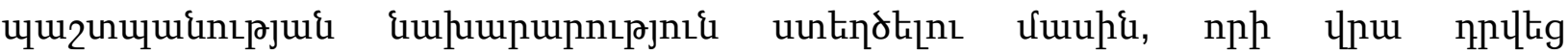

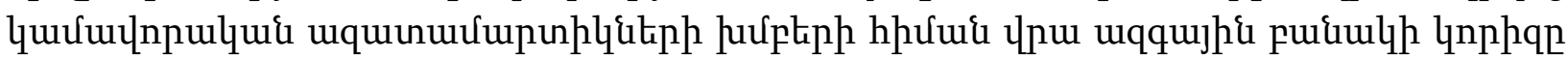

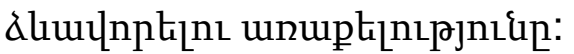

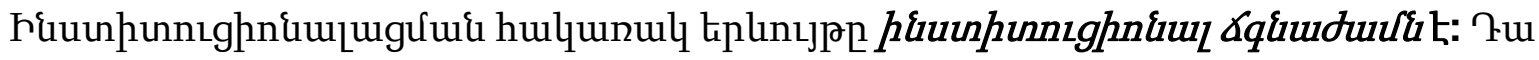

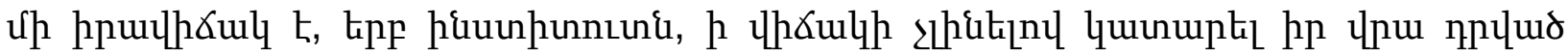

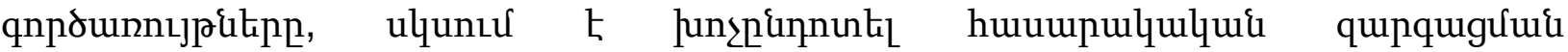

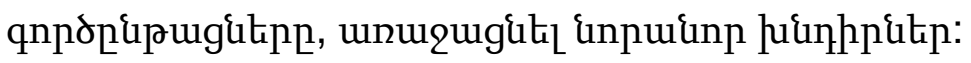

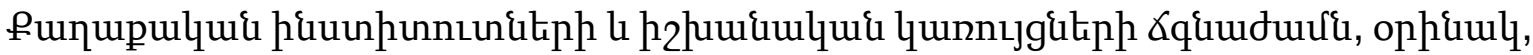

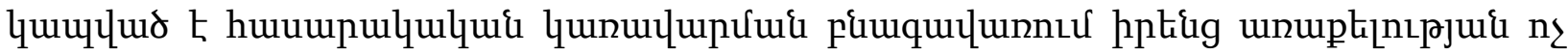

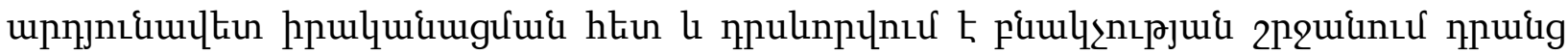

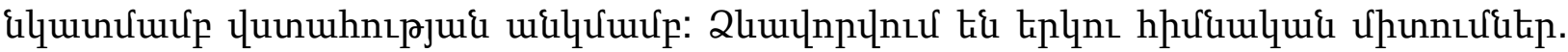

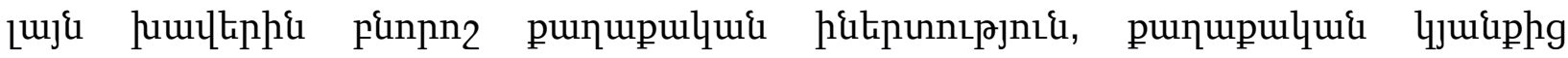

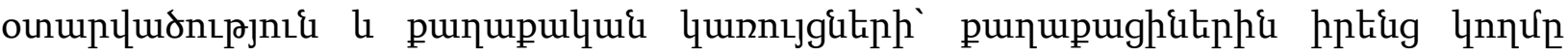

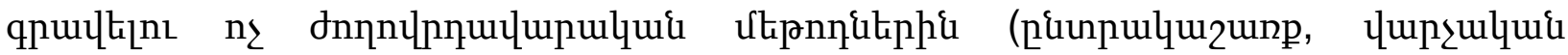

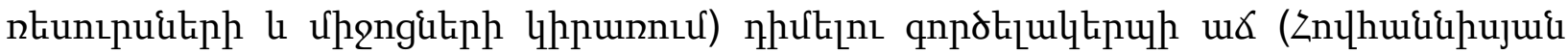
2003: 11-12):

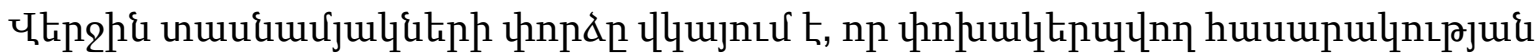

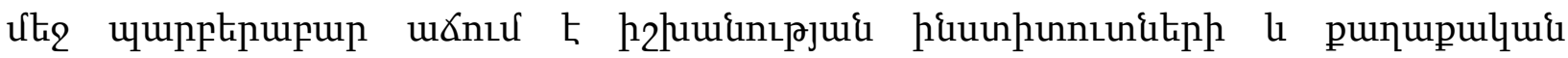

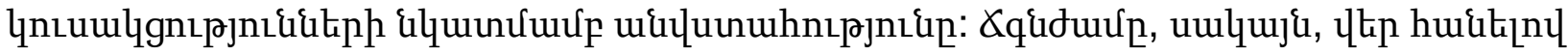

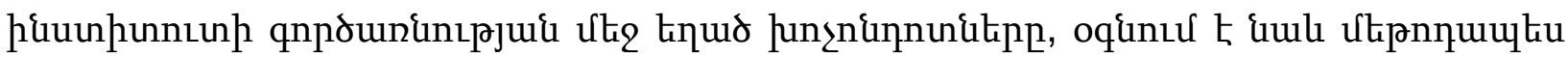

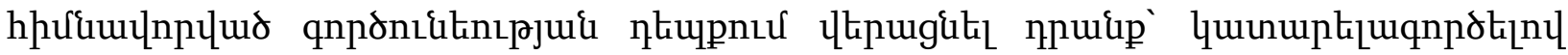

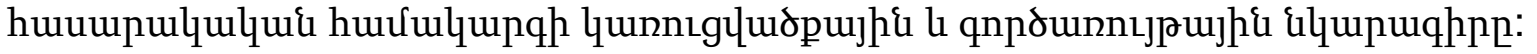

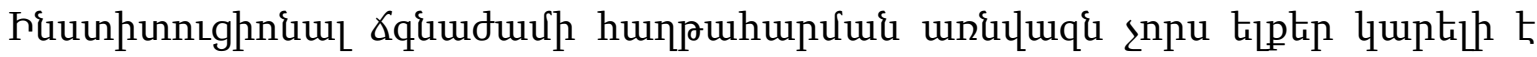
unuidàlaughitil.

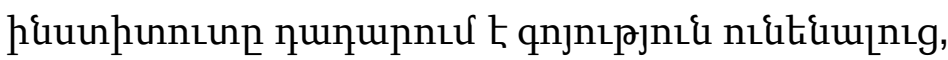

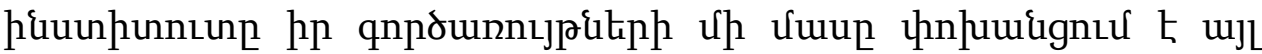
hquunhunnump,

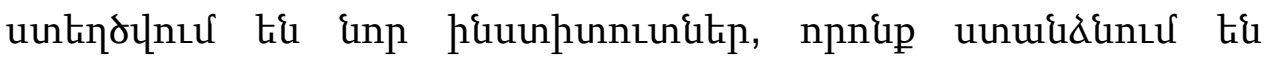

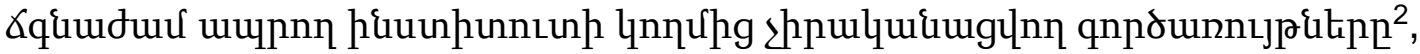




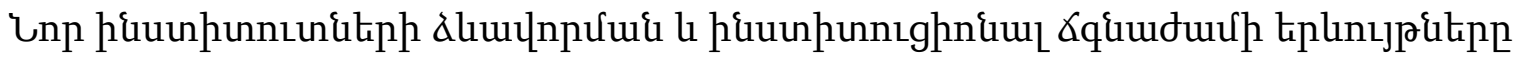

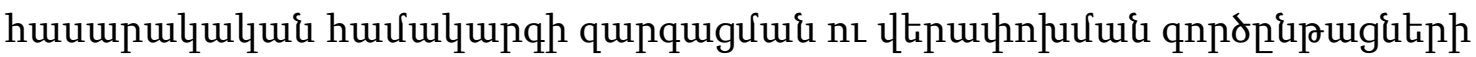

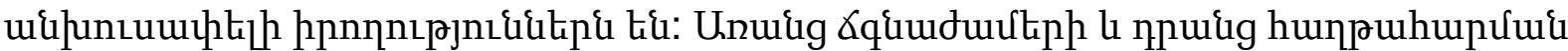
ndu unurpipugn:

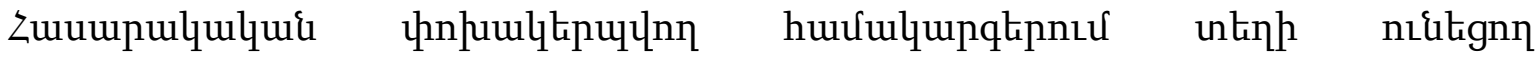

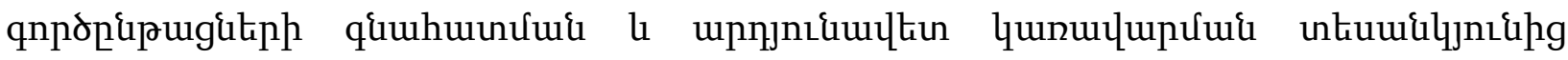

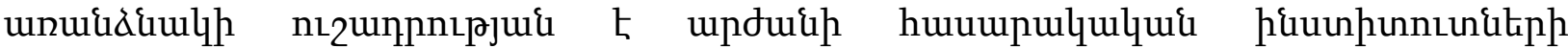

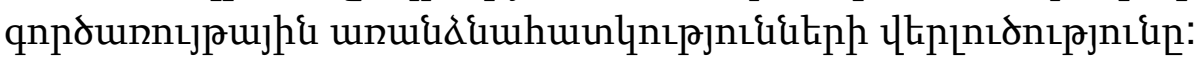

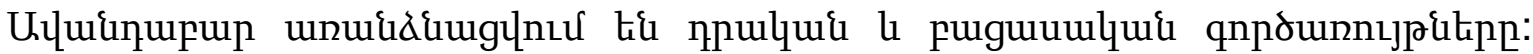

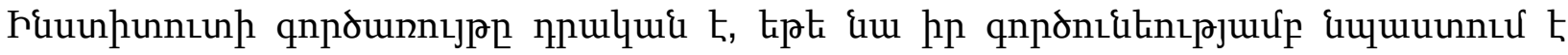

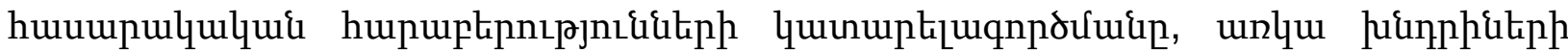

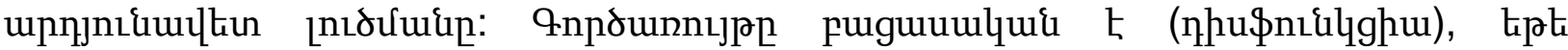

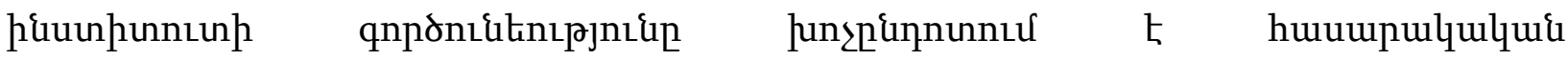

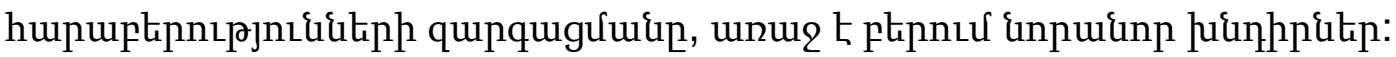

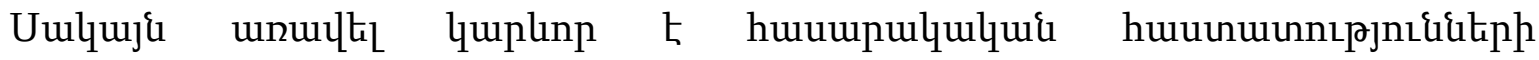

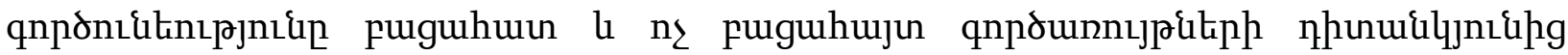

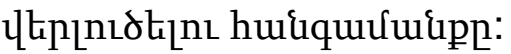

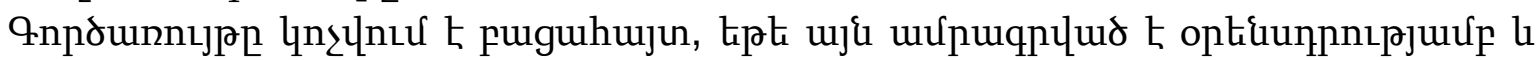

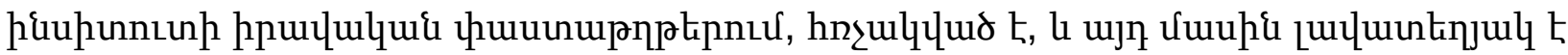

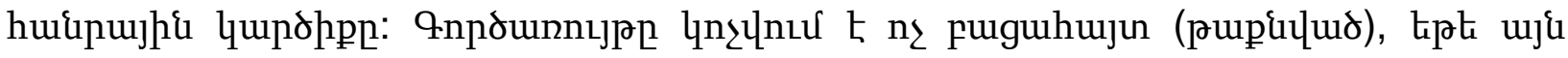
uर्upuqpuluz 25

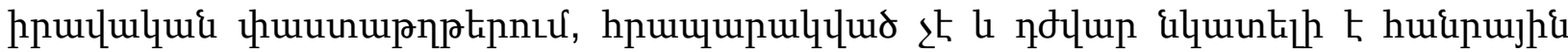
quipלhph hưưup (Мертон 1996):

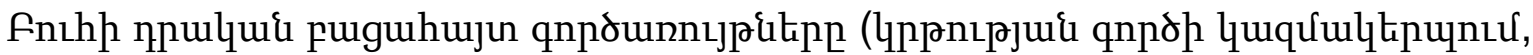

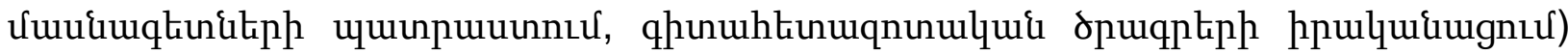

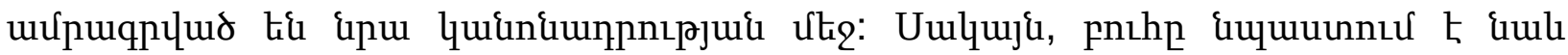

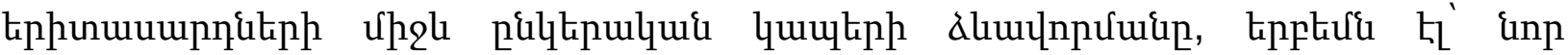

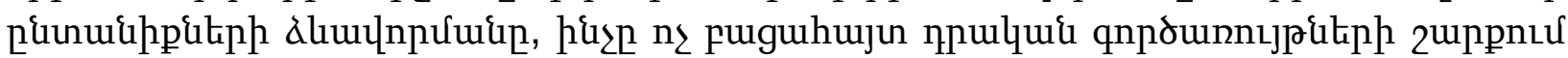

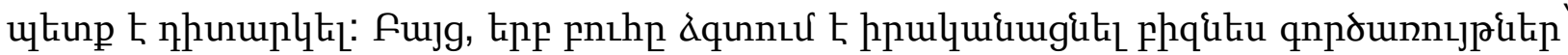

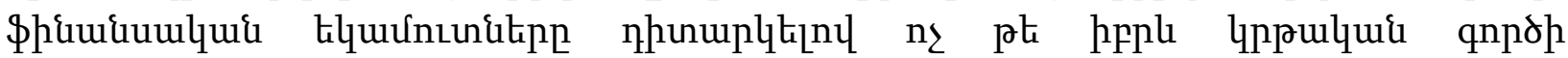

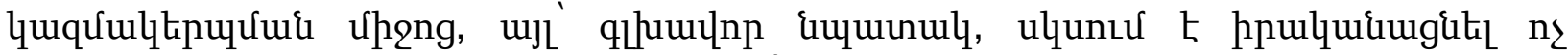

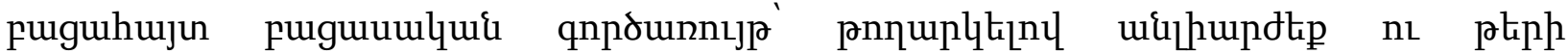
unuquuqtinitip:

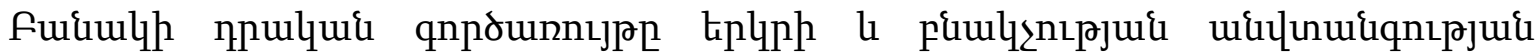

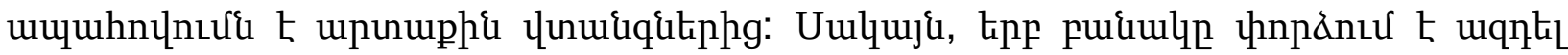

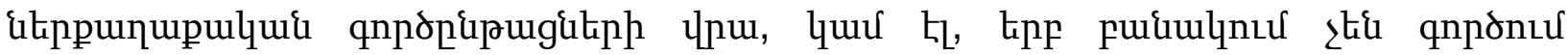

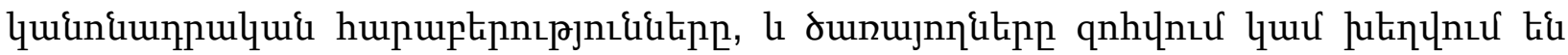

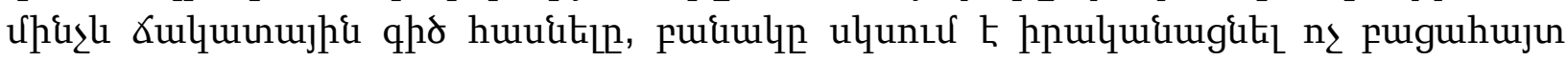
nhu\$nı\&lighuilin:

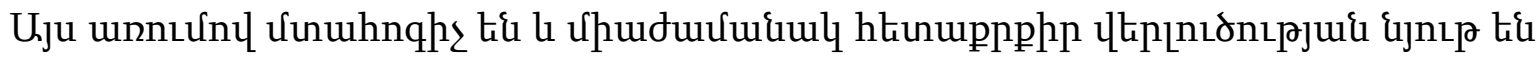

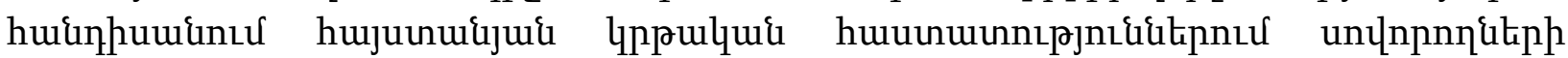




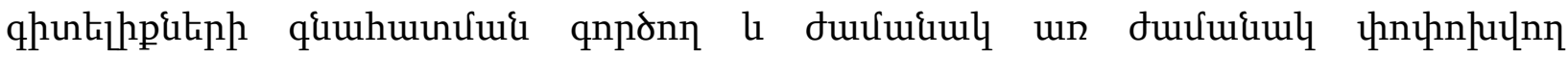
uuinnulqutin:

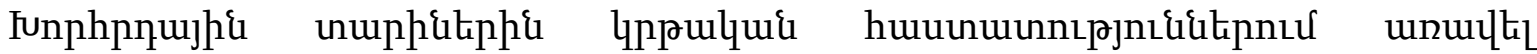

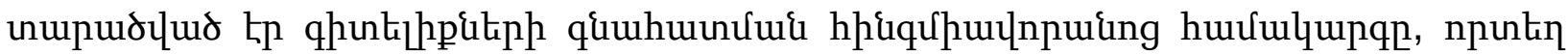

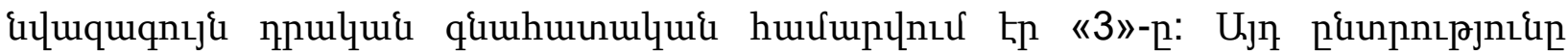

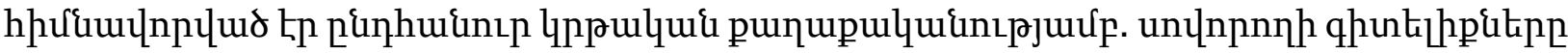

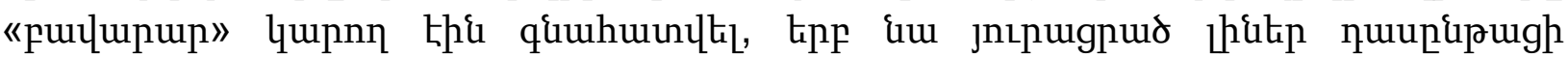

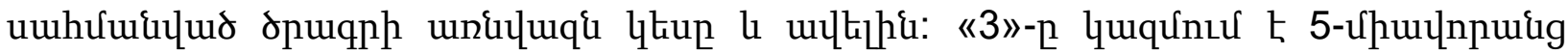
uuinnulih 60\%-n:

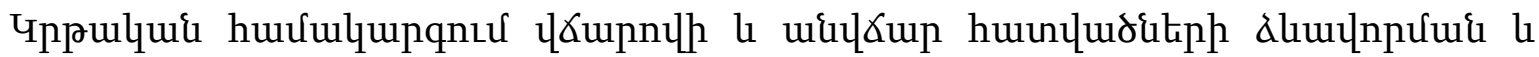

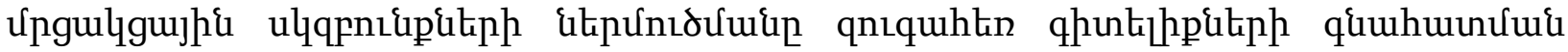

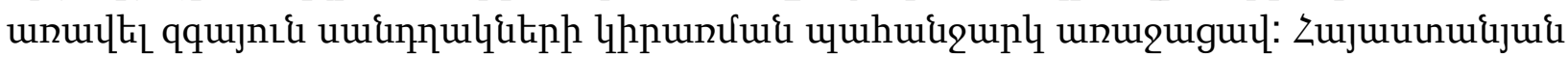

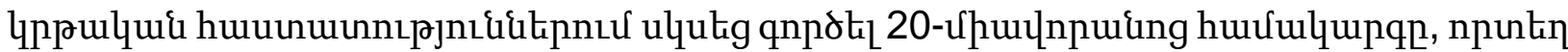

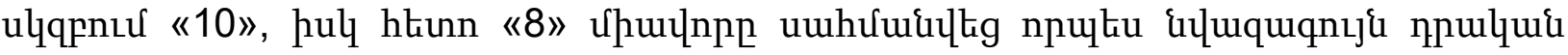

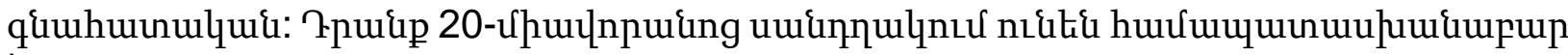

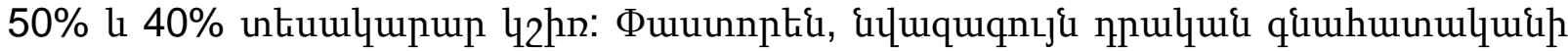

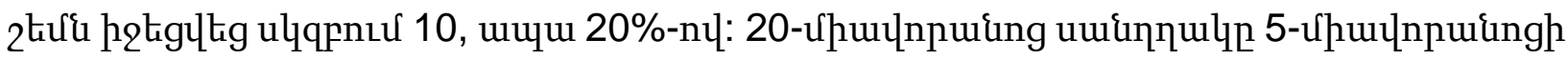

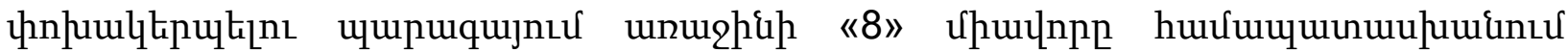

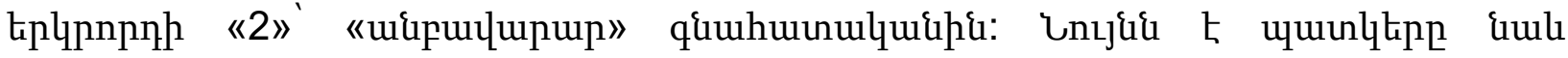

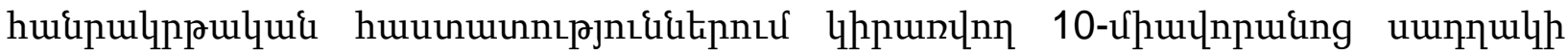

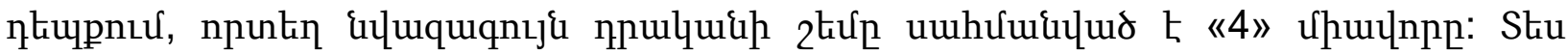
Unjniuul 1:

\section{Unjnıuuly 1.}

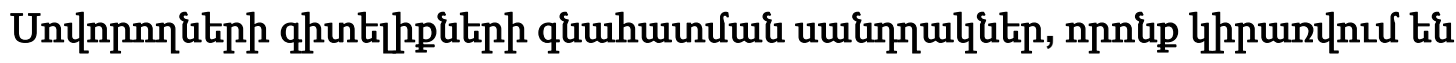
lppulquif huuunuunnıpjnı\&ilipnud

\begin{tabular}{|l|l|l|}
\hline 1 & 1 & 1 \\
2 & 2 & 2 \\
& $\cdot$ & 3 \\
4 & $8 \rightarrow 60 \%$ & $4 \rightarrow 40 \%$ \\
5 & $8 \rightarrow 40 \%$ & 5 \\
& $10 \rightarrow 50 \%$ & 6 \\
& $\cdot$ & 7 \\
& - & 8 \\
& 20 & 9 \\
\hline
\end{tabular}

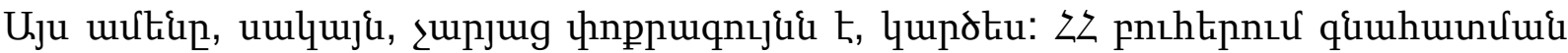

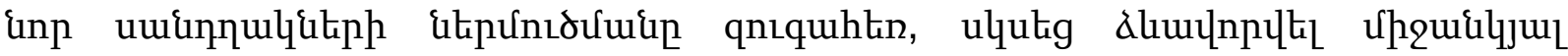

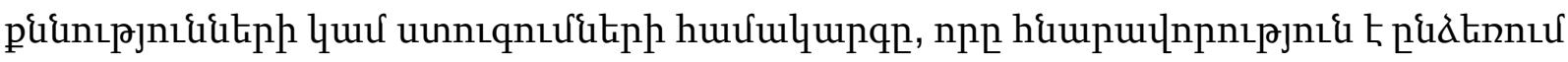

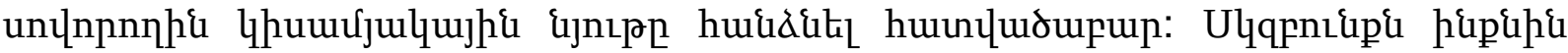

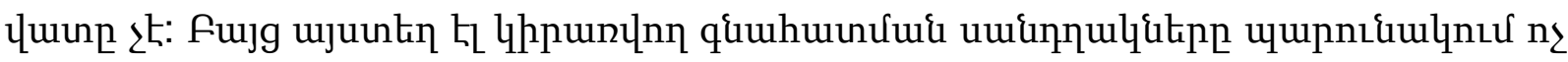
puguhuujun nhu\$niqughuiktp: 


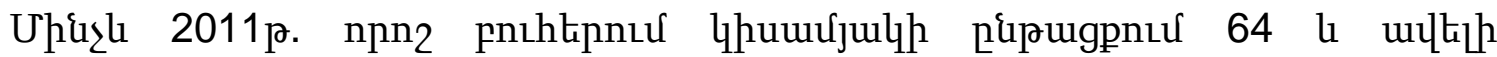

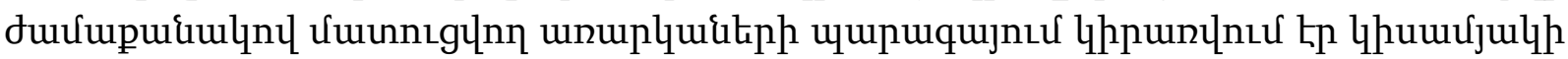

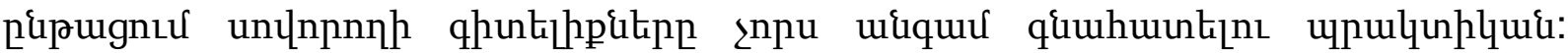

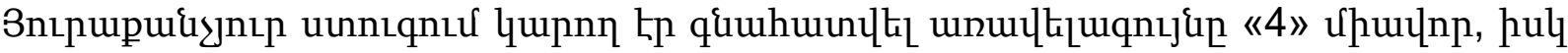

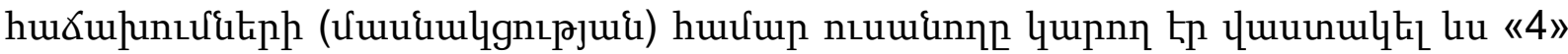

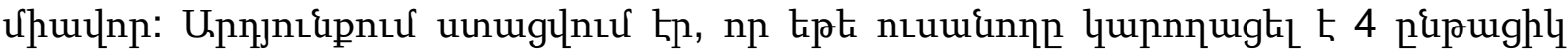

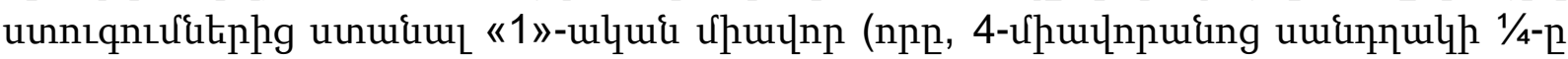

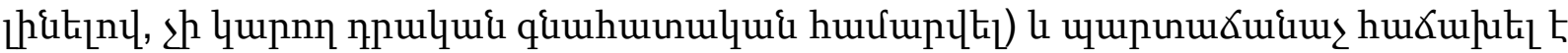

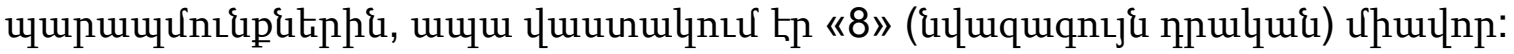

Stu Unjnıuul 2:

\section{Unjnuuuly 2.}

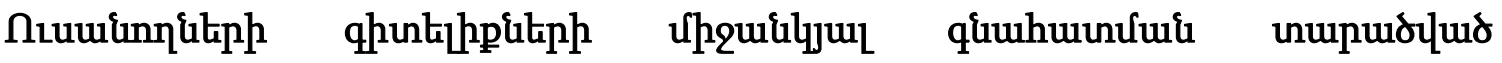
ulqpniupitiphg uttlp lu hiupuulnp tipp

\begin{tabular}{|c|c|c|c|c|c|}
\hline $\begin{array}{c}\text { 1-hid } \\
\text { uunntqnux }\end{array}$ & $\begin{array}{c}\text { 2-pn } \\
\text { uunntqnıu }\end{array}$ & $\begin{array}{c}\text { 3-nn } \\
\text { uunnıqnuर }\end{array}$ & $\begin{array}{c}\text { 4-pn } \\
\text { uunntqnuर्u }\end{array}$ & $\begin{array}{l}\text { Uuuuduul- } \\
\text { gnıpjnıq }\end{array}$ & $\begin{array}{c}\text { Uưuhnuhhર } \\
\text { quuhumunulquut }\end{array}$ \\
\hline$« 4 »$ & $\langle 4 »$ & «4» & «4» & «4» & «20» \\
\hline$《 1 »$ & «1» & $《 1 »$ & $《 1 »$ & «4» & «8» \\
\hline
\end{tabular}

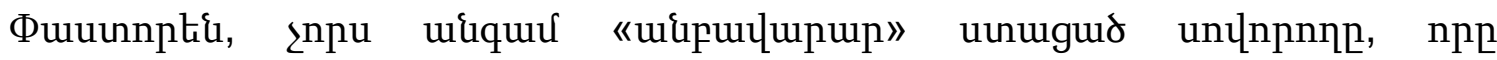

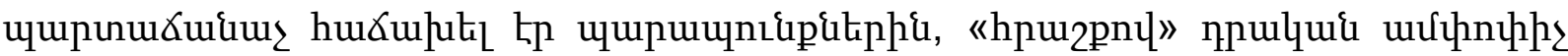

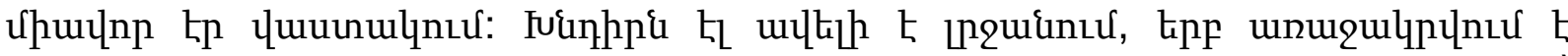

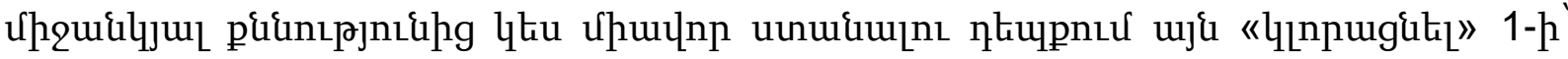
unцnnnnh oqunpi:

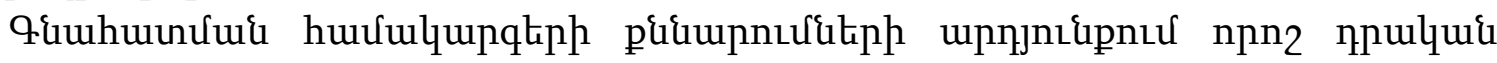

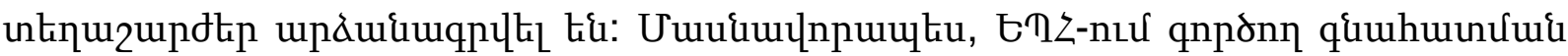

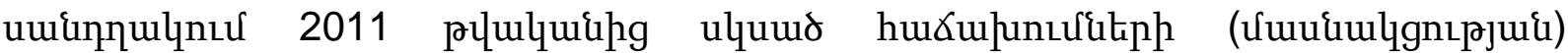

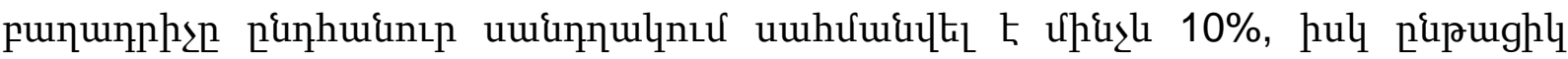

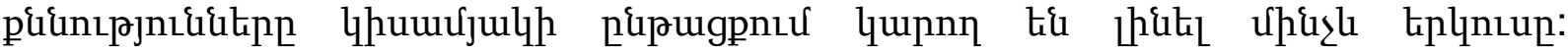

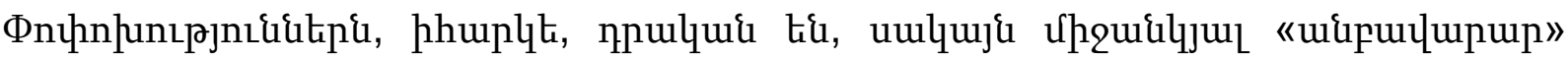

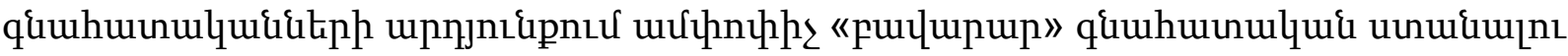

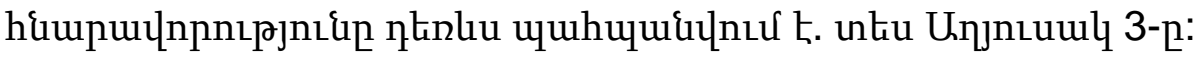

\section{Unjnıuuly 3.}

\begin{tabular}{|c|c|c|c|c|}
\hline 1-hi uunnıqnux & 2-pn unnıqniu & 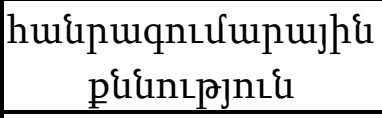 & Uuuufuulgnıpjnı\{ & 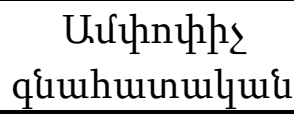 \\
\hline$« 4 »$ & «4» & «8» & «2» & «20» \\
\hline «1» & «1» & «2» & «2» & «8» \\
\hline
\end{tabular}




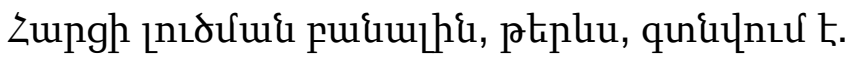

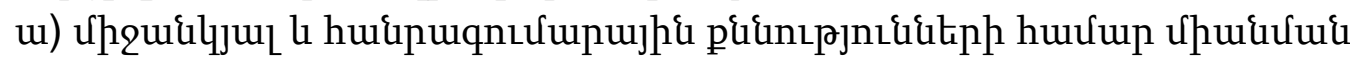
uuinnulqukph lhpunúuid,

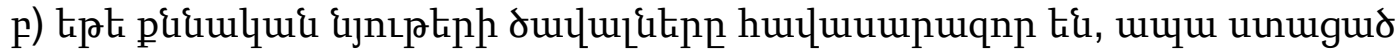

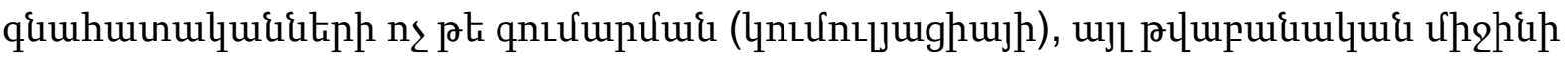

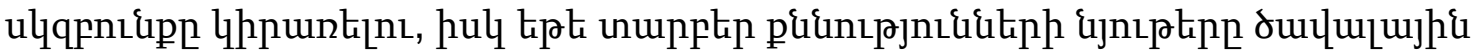

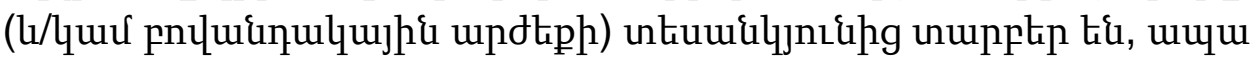

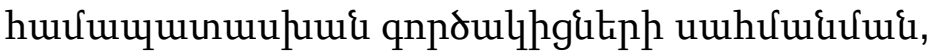

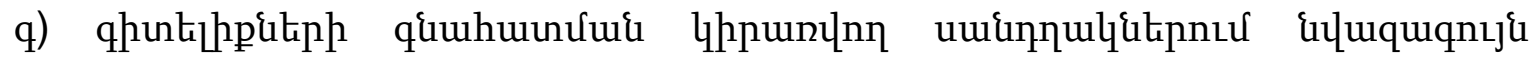

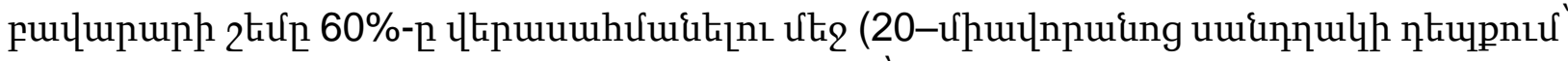

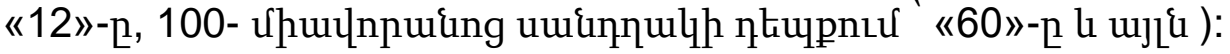

Ujuuhunц, hnhuulı

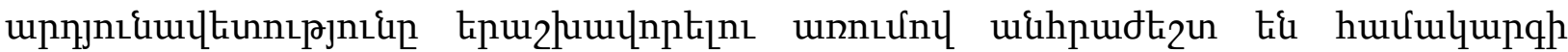

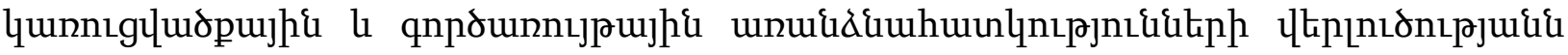

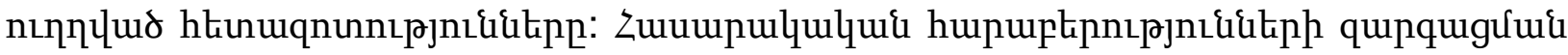

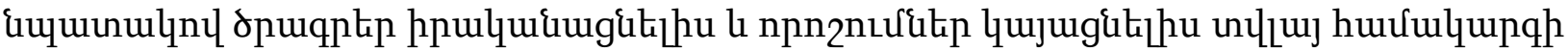

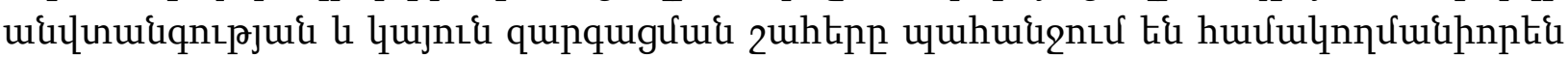

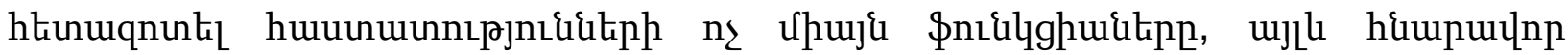

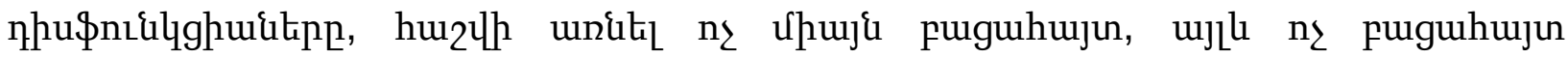

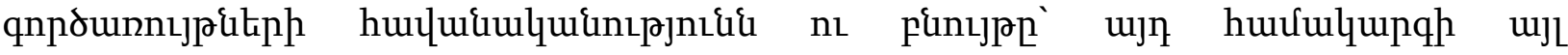

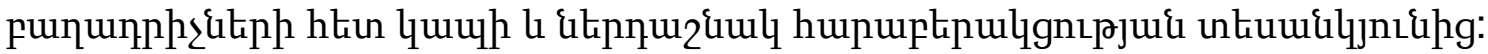

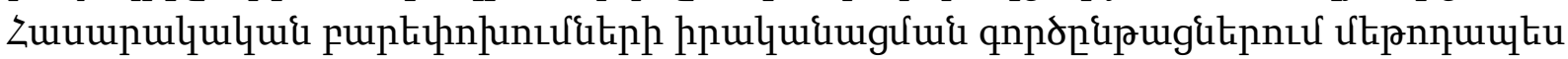

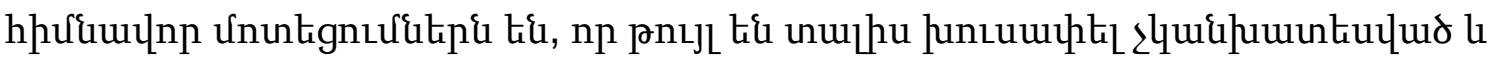

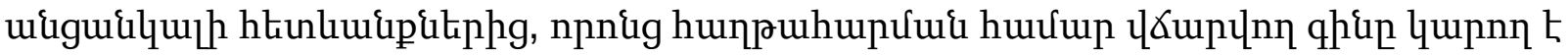

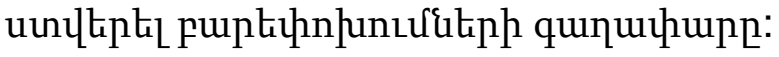

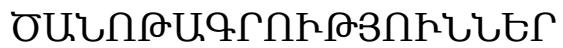

${ }^{1}$ Strengthening Civil Society and its Interaction with State Institutions. Policy Paper. European Union Advisory Group to the Republic of Armenia. Septembre, 2012.

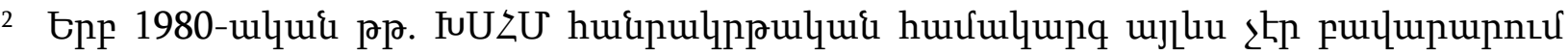

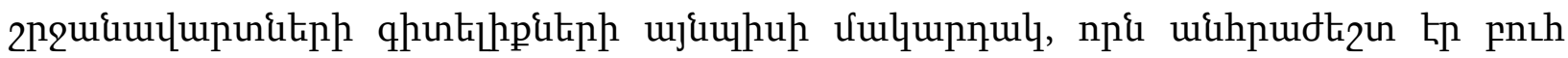

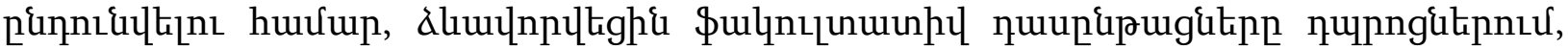

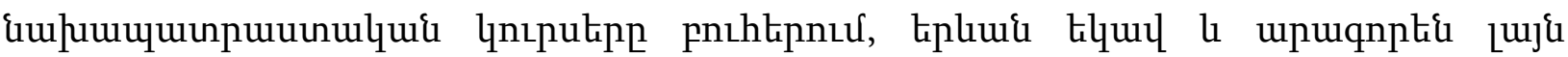

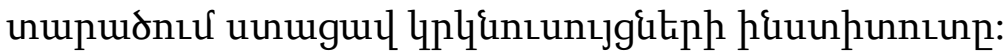

